\title{
Effects of lockdown during corona pandemic on children with neurodevelopmental disorders-A questionnaire-based survey
}

\author{
Jyotindra Narayan Goswami ${ }^{1 \oplus}$, Vishal Sondhi ${ }^{2 \oplus}$, Ashish Kumar Simalti ${ }^{3 \oplus}$, \\ Manu Bamal ${ }^{1 \oplus}$, Shuvendu Roy ${ }^{4 \oplus}$ \\ ${ }^{1}$ Department of Pediatrics, Army Hospital (Research \& Referral), New Delhi; ${ }^{2}$ Department of Pediatrics, Armed Forces Medical College, \\ Pune; ${ }^{3}$ Department of Pediatrics, MH Dehradun, Uttarakhand; ${ }^{4}$ Department of Pediatrics, Command Hospital (EC), Kolkata, India.
}

\begin{abstract}
Background. Lockdown due to Corona pandemic is an unprecedented event, which has had a profound impact on the lives of children across all ages. Its effects on children with Neurodevelopmental Disorders (NDD) has not been adequately studied. This study was performed in order to explore the effects of lockdown during the Corona pandemic on children with NDD and their parents.

Methods. The survey was conducted in three Indian tertiary-care hospitals wherein parents of children with NDD were requested to respond to an online questionnaire. The questions attempted to elicit various aspects of the children's therapies and behavioural profiles as well as their parents' experiences during the pandemic related lockdown.

Results. 135/188 (71.8\%) parents of children with Autism Spectrum Disorder (ASD)(n=104), Attention Deficit Hyperactivity Disorder (ADHD) (n=26) and Learning Disability (LD)(n=5) responded. Pre-lockdown, 133 (99\%) children were receiving regular institution-based therapy, which ceased intra-lockdown. Mean cumulative home-based therapy duration significantly increased during lockdown $(p=0.03)$. Parents reported significantly increased temper tantrums in children $(\mathrm{p}=0.02)$. They perceived that during lockdown, their children were bored and their interactions and speech worsened. Majority of parents reported worsening of own qualities of life, but felt confident of taking care of their children during lockdown.

Conclusions. To conclude, children with NDD and their parents were significantly affected by Corona pandemicrelated lockdown. Institutional therapy discontinuation, behavioural deterioration (especially among ASD and ADHD) and parental stress were prominent challenges whereas parental motivation and reliance on homebased therapy were the positive highlights. The survey points to the role of regular parent-administered homebased therapy in children with NDD, especially to tide over similar unexpected adverse scenarios.
\end{abstract}

Key words: corona pandemic, COVID-19, lockdown, neurodevelopmental disorders.

Coronavirus-2019 Disease (COVID-19) caused by Severe Acute Respiratory Syndrome Coronavirus 2 (SARS-CoV-2) was declared as a global epidemic by World Health Organization (WHO) on 11 March 2020. ${ }^{1}$ Lockdown was an unprecedented, emergency measure, which

$凶$ Shuvendu Roy

nephroneuro@gmail.com

Received 1st December 2020, revised 25th December 2020, accepted 11th January 2021. was adopted across several countries to prevent the exponential spread of the disease. India was placed under lockdown from 24 March 2020, which was extended till 31 May 2020 with subsequent gradual relaxation of restrictions. At the time of submission of this article (16 August 2020), a partial lockdown was in vogue in India. Lockdown is having profound repercussions on day-to-day functioning of people from all walks of life, including children. Children with neurodevelopmental disorders (NDD) constitute a sizeable segment 
of pediatric population with high healthcare service requirements compared to the general population. ${ }^{2}$ Discontinuation of almost all services except skeletal emergency services, socioeconomic implications, compounded with the disruption of daily routine and a novel, uncertain environment are likely to have varied effects on children with NDD depending on their underlying neurological diagnoses and disease severity. Parents/primary caregivers are also likely to be affected. These effects are hitherto unknown. Hence, our study was formulated in this backdrop to explore the salient effects of lockdown during the COVID-19 pandemic on children with NDD.

\section{Material and Methods}

\section{Study design and population}

This online cross-sectional survey was conducted simultaneously at three tertiary care referral hospitals in India having pediatric neurology services. The Institutional Ethical Committee approved the study and it was registered with the Clinical Trials Registry- India (CTRI) (No: CTRI/2020/06/025795). All parents/primary caregivers of children diagnosed with either Autism Spectrum Disorder (ASD), Attention Deficit Hyperactivity Disorder (ADHD) or Learning Disorder (LD) who were on followup at any of the three centers were approached telephonically for participation. The children were excluded if they had any coexisting neurodegenerative or neuromuscular disorder.

\section{Procedure}

A pragmatic anonymized survey was developed and piloted by authors (JNG, SR). The questions were thereafter hosted online (Google Form ${ }^{\mathrm{TM}}$ ) between 15 April 2020 to 15 June 2020. Parental consent was obtained. A participant information page was included at the beginning of the survey. The survey included 21 questions (Table I) and a 5-point Likert Scale having 10 questions (Table II). If the parents/primary caregivers agreed to participate in the survey, the online
Google Form link was shared with them. If they did not respond within the subsequent 72 hours, then two reminder telephone calls 72 hours apart were made. If they still did not fill the online form after a total of three telephone calls, no further attempts were made to contact them. For parents/primary caregivers who were uncomfortable with online filling of the form, telephonic assistance for filling the form was provided.

\section{Outcome measures}

The primary outcome of the study was to assess the effect of COVID-19 related lockdown on children with ASD, ADHD, and LD. The secondary objective of the study was to assess the effects of the lockdown on the parents/ primary caregivers of these children.

\section{Statistical analysis}

Continuous data were presented as mean \pm Standard Deviation (SD) and categorical data were expressed as number (\%). Group differences were tested using Chi-square test and Wilcoxon rank sign test. All statistical analyses were performed using SPSS software (version 20.0, IBM), p values < 0.05 were considered statistically significant.

\section{Results}

Among 188 families that were contacted, 135 (71.8\%) responded. These included 104 children with ASD ( 82 boys), 26 with ADHD (20 boys) and 5 with LD (3 boys). Table III outlines the baseline characteristics of participating children. Respondents included 83 (51\%) fathers and 52 $(49 \%)$ mothers (statistically similar; $\mathrm{p}=0.41)$.

\section{Therapies}

Prior to implementation of lockdown, some form of institution-based therapy was being regularly administered to 133 children (99\%) (Fig. 1). These included occupational therapy $[\mathrm{ASD}=101(97 \%), \mathrm{ADHD}=3(12 \%), \mathrm{LD}=0]$, speech therapy $[\mathrm{ASD}=82(79 \%), \mathrm{ADHD}=5$ 
Table I. Parental questionnaire.

1. My child is a (boy/girl).

2. His/her is.........years.........months old.

3. He/she is under follow-up of pediatric neurology OPD since

4. My child is a patient of .....

5. His/her total average daytime sleep duration (in hours) was............. and total average night-time sleep duration (in hours) was prior to lockdown.

6. His/her total average daytime sleep duration (in hours) is. and total average night-time sleep duration (in hours) was during lockdown.

7. He /she had sleep problems prior to lockdown. (Yes/No)

8. He/she is having sleep problems during lockdown. (Yes/No)

9. He/she had feeding issues prior to lockdown. (Yes/No)

10. He/she is having feeding issues during lockdown. (Yes/No)

11. He she had significant temper tantrums prior to lockdown. (Yes/No)

12. He/she is having significant temper tantrums during lockdown. (Yes/No)

13. He/she used to receive following institutional therapy/therapies regularly before lockdown

14. Among therapies mentioned in Serial No 13, following are not being administered during lockdown

15. Total average weekly institutional therapy/therapies administered to the child prior to lockdown was....................hours/week.

16. Total average weekly institutional therapy/therapies administered to the child during lockdown is....................hours/week.

17. He/she used to receive following therapy/therapies regularly at home before lockdown

18. Among therapies mentioned in Serial No 17, following are not being administered during lockdown

19. Total average weekly home-based therapy/therapies administered to the child prior to lockdown was.. hours/week.

20. Total average weekly home-based therapy/therapies administered to the child during lockdown is...................hours/week.

21. Child was getting ................number of drugs daily before lockdown. During lockdown ..drugs were not given

OPD: outpatient department

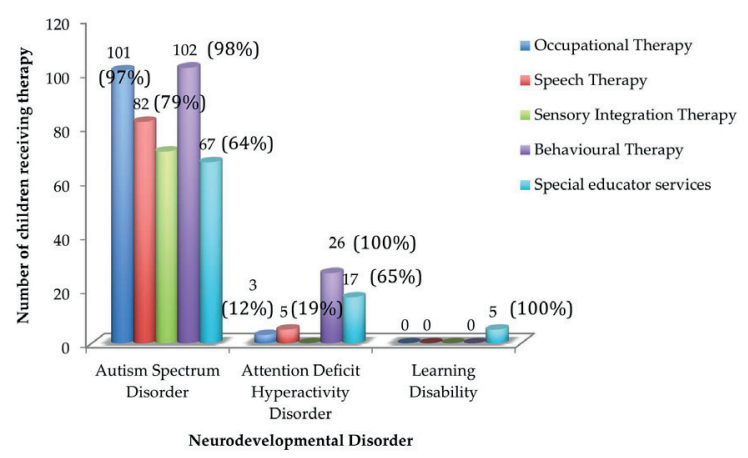

Fig. 1. Clustered bar diagram displaying institutionbased therapies administered to children with NDD prior to lockdown.
$(19 \%), L D=0]$, sensory integration therapy [ASD $=71(68 \%)$, ADHD $=0, \mathrm{LD}=0)$, behavioral services $[\mathrm{ASD}=102(98 \%), \mathrm{ADHD}=26(100 \%)$, $\mathrm{LD}=0]$ and special educator services [ASD $=67(64 \%), \quad$ ADHD $=17(65 \%), \quad$ LD $=5(100 \%]$. During lockdown, no child could avail of institution-based interventions as these facilities were temporarily suspended. Hence, difference between the pre-lockdown and intra-lockdown mean cumulative institution-based therapies administered to the children was significant $(\mathrm{p}=0.02$, Table IV). 
Table II. Parental Likert scale.

\begin{tabular}{|c|c|c|c|c|c|c|}
\hline \multicolumn{7}{|c|}{ Part A } \\
\hline \multirow[b]{2}{*}{$\begin{array}{l}\text { Serial } \\
\text { number }\end{array}$} & \multirow[b]{2}{*}{ Question } & \multicolumn{5}{|c|}{ Choose one of the following responses } \\
\hline & & $\begin{array}{l}\text { (A) } \\
\text { Totally } \\
\text { agree }\end{array}$ & $\begin{array}{l}\text { (B) } \\
\text { Somewhat } \\
\text { agree }\end{array}$ & $\begin{array}{c}\text { (C) } \\
\text { No } \\
\text { comment }\end{array}$ & $\begin{array}{c}\text { (D) } \\
\text { Partly } \\
\text { disagree }\end{array}$ & $\begin{array}{c}(\mathrm{E}) \\
\text { Totally } \\
\text { disagree }\end{array}$ \\
\hline 1 & $\begin{array}{l}\text { I feel as confident of taking care of } \\
\text { my child during lockdown as before }\end{array}$ & & & & & \\
\hline 2 & $\begin{array}{l}\text { My child appears to be bored } \\
\text { during major part of the day during } \\
\text { lockdown }\end{array}$ & & & & & \\
\hline 3 & $\begin{array}{l}\text { Home-based therapy given to my } \\
\text { child during lockdown is inadequate } \\
\text { for him/her }\end{array}$ & & & & & \\
\hline 4 & $\begin{array}{l}\text { Lockdown has adversely affected } \\
\text { my child's therapy }\end{array}$ & & & & & \\
\hline \multicolumn{7}{|c|}{ Part B } \\
\hline \multicolumn{7}{|c|}{ Choose one of the following responses } \\
\hline $\begin{array}{l}\text { Serial } \\
\text { number }\end{array}$ & Question & $\begin{array}{c}\text { (A) } \\
\text { Significantly } \\
\text { worse }\end{array}$ & $\begin{array}{l}\text { (B) } \\
\text { Somewhat } \\
\text { worse }\end{array}$ & $\begin{array}{c}\text { (C) } \\
\text { Neutral }\end{array}$ & $\begin{array}{l}\text { (D) } \\
\text { Somewhat } \\
\text { better }\end{array}$ & $\begin{array}{c}\text { (E) } \\
\text { Significantly } \\
\text { better }\end{array}$ \\
\hline 1 & $\begin{array}{l}\text { My overall quality of life during } \\
\text { lockdown compared to what it was } \\
\text { prior to lockdown }\end{array}$ & & & & & \\
\hline 2 & Child's speech during lockdown & & & & & \\
\hline 3 & $\begin{array}{l}\text { Child's sleep-related problems } \\
\text { during lockdown }\end{array}$ & & & & & \\
\hline 4 & $\begin{array}{l}\text { Child's temper tantrums during } \\
\text { lockdown }\end{array}$ & & & & & \\
\hline 5 & $\begin{array}{l}\text { Child's interaction with parents and } \\
\text { sibling(s) during lockdown }\end{array}$ & & & & & \\
\hline 6 & $\begin{array}{l}\text { My child's behavioural problems } \\
\text { during lockdown compared to those } \\
\text { before lockdown }\end{array}$ & & & & & \\
\hline
\end{tabular}

Though parents of all children with NDD were advised home-based therapy as a part of institutional protocol, the number of children actually being administered some form of home-based therapy was variable. Details of pre-lockdown and intra-lockdown home-based therapy are illustrated in Fig. 2. The mean cumulative duration of home-based therapies administered to the entire cohort of children with NDD during lockdown was significantly greater than that being administered prior to lockdown ( $\mathrm{p}=0.03$, Table IV).
The number of children with ASD who received home-based therapy during pre-lockdown and intra-lockdown periods was comparable. These therapies included home-based occupational therapy (pre-lockdown: 62, intra-lockdown: 70, $\mathrm{p}=0.25)$, home-based sensory integration therapy (pre-lockdown: 10, intra-lockdown: $12, \mathrm{p}=0.65$ ), home-based behavior therapy (prelockdown: 50, intra-lockdown: 55, $\mathrm{p}=0.49$ ) and home-based special educator services (prelockdown: 2, intra-lockdown: 2, p=1). Similarly, pre-lockdown and intra-lockdown variations in the numbers of children with ADHD receiving 
Table III. Demographic profile of children with neurodevelopmental disorders enrolled in the study.

\begin{tabular}{lll}
\hline Gender & Boys: 105, Girls: 30 & \\
\hline Neurological Diagnosis & Autism Spectrum Disorder (ASD) & 104 (boys: 82, girls: 22) \\
& Attention Deficit Hyperactivity & 26 (boys: 20, girls: 6) \\
& $\begin{array}{l}\text { Disorder (ADHD) } \\
\text { Learning Disability (LD) }\end{array}$ & 5 (boys: 3, girls: 2) \\
& 1-3 years & ASD: 9 ADHD: 3 LD: 0 \\
Age bands & $4-6$ years & ASD: 31 ADHD: 6 LD: 0 \\
& $7-9$ years & ASD: 49 ADHD: 13 LD: 1 \\
& 10-12 years & ASD: 15 ADHD: 4 LD: 4 \\
Mean duration of prior follow-up & ASD & 23 (QI: 7, Q3: 54) \\
in OPD & ADHD & 19 (Q1: 3, Q3: 26) \\
$\begin{array}{l}\text { (Median, 1st quartile,3rd quartile } \\
\text { in months) }\end{array}$ & LD & 47 ( Q1: 32, Q3: 63) \\
$\begin{array}{ll}\text { Children receiving } \\
\text { pharmacotherapy pre-lockdown }\end{array}$ & ASD & 78 (1 drug: 45, 2 drugs: 33) \\
Children who had discontinuation & ASD & 26 (1 drug: 3, 2 drugs: 14, 3 drugs: 9) \\
$\begin{array}{l}\text { of pharmacotherapy during } \\
\text { lockdown }\end{array}$ & ADHD & 0 \\
\hline
\end{tabular}

OPD: outpatient department
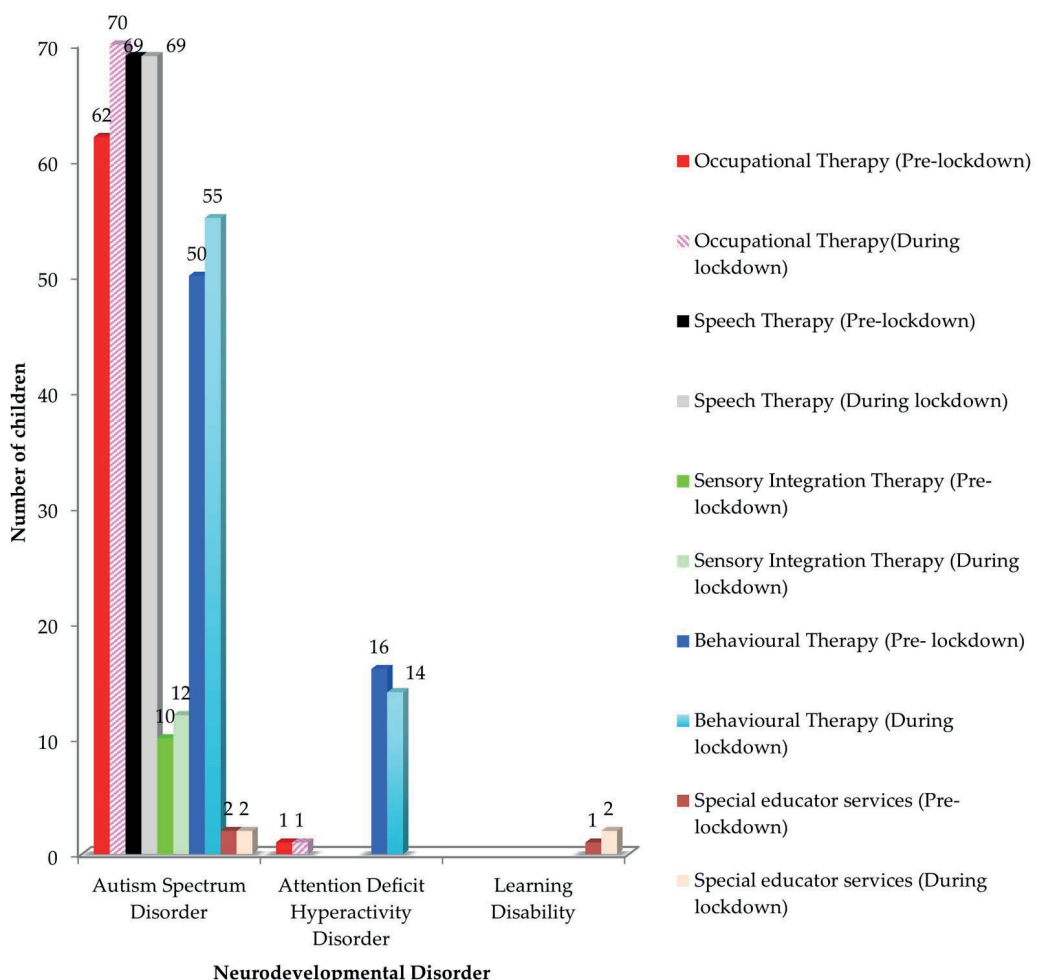

Neurodevelopmental Disorder

Fig. 2. Clustered bar diagram representing home-based interventions administered to children with NDD prior to implementation of lockdown and during lockdown period. 
Table IV. Tabular representation of key target behaviours of enrolled children and the various therapies offered to them prior to and during lockdown period (based on parental response).

\begin{tabular}{|c|c|c|c|}
\hline Variable & Pre-lockdown & During lockdown & $p$ value \\
\hline $\begin{array}{l}\text { Daily mean cumulative sleep duration (night) } \\
\text { (hours) }\end{array}$ & $\begin{array}{c}8.8 \\
(\mathrm{Q} 1: 7.5, \mathrm{Q} 3: 9 ; \mathrm{SD}: 2.4)\end{array}$ & $\begin{array}{c}7.3 \\
(\mathrm{Q} 1: 6, \mathrm{Q} 3: 9 ; \mathrm{SD}: 3)\end{array}$ & 0.7 \\
\hline $\begin{array}{l}\text { Daily mean cumulative sleep duration (daytime) } \\
\text { (hours) }\end{array}$ & $\begin{array}{c}3.2 \\
(\mathrm{Q} 1: 1.4, \mathrm{Q} 3: 4 ; \mathrm{SD}: 2.1)\end{array}$ & $\begin{array}{c}2.7 \\
(\mathrm{Q} 1: 1.9, \mathrm{Q} 3: 3 ; \mathrm{SD}: 1.8)\end{array}$ & 0.86 \\
\hline $\begin{array}{l}\text { Number of children with parentally reported sleep } \\
\text { problems }\end{array}$ & 96 & 82 & 0.72 \\
\hline $\begin{array}{l}\text { Number of children with parentally reported } \\
\text { feeding issues }\end{array}$ & 82 & 94 & 0.13 \\
\hline $\begin{array}{l}\text { Number of children with parentally reported } \\
\text { significant temper tantrums }\end{array}$ & 108 & 122 & 0.02 \\
\hline $\begin{array}{l}\text { Mean duration of consolidated institutional } \\
\text { occupational therapy (occupation }+ \text { speech }+ \\
\text { behavioral therapy) (hours/week) }\end{array}$ & $\begin{array}{c}5.4 \\
(\mathrm{Q} 1: 2.5, \mathrm{Q} 3: 7 ; \mathrm{SD}: 3.7)\end{array}$ & 0 & 0.02 \\
\hline $\begin{array}{l}\text { Mean duration of Home -based intervention } \\
\text { (hours/week) }\end{array}$ & $\begin{array}{c}11.2 \\
(\mathrm{Q} 1: 7.8, \mathrm{Q} 3: 15.2 ; \mathrm{SD}: \\
5.4)\end{array}$ & $\begin{array}{c}15 \\
(\mathrm{Q} 1: 8.1, \mathrm{Q} 3: 18.3 ; \mathrm{SD}: \\
4.6)\end{array}$ & 0.3 \\
\hline
\end{tabular}

Q1: first quartile, Q3: third quartile, SD: standard deviation

home-based therapy [occupational therapy (pre-lockdown: 1, intra-lockdown: 1, p=1), behaviour therapy (pre-lockdown: 16, intralockdown: 14, $\mathrm{p}=0.32$ )] and those with LD receiving home-based special education (prelockdown: 1 , intra- lockdown: $2, \mathrm{p}=0.48$ ) were statistically insignificant.

\section{Behavioural changes}

Parents reported a significant increase in their children's temper tantrums during lockdown $(p=0.02$, Table IV). No significant biorhythm alteration was noted in the children. Prelockdown and intra-lockdown sleep patterns were similar with comparable daytime and nocturnal sleep durations and sleep related problems. Though greater number of children were reported to have feeding issues during lockdown period compared to that during prelockdown period, the difference was statistically insignificant $(\mathrm{p}=0.3$, Table IV).

\section{Parental Perceptions}

Parental responses to the Likert Scale questionnaire have been represented through Fig. 3, Fig. 4 while a diagnosisbased stratification of the core responses are represented through Table $\mathrm{V}$. The percentages of parents of children with ASD/ADHD/LD who responded to the various questions as 'agreed' were similar $(\mathrm{N}=30 ; \mathrm{p}=0.20)$. Percentages of parents who responded as 'disagreed' were also similar $(\mathrm{N}=30 ; \mathrm{p}=0.39)$. When comparing across the groups, the results are significant [H statistic is $15.8393(4, \mathrm{~N}=50), \mathrm{p}: 0$.00324]. Significantly larger number of parents/primary caregivers felt that lockdown affected their children's therapy adversely (Table V). Subclass analysis revealed that this difference was not significant in the responses of parents/primary caregivers of children with LD $(\mathrm{p}=0.22)$. Significant proportion of parents/primary caregivers responded that their children were bored during lockdown and that their behavioral problems, interactions with parents and peers, temper tantrums and sleep related issues had worsened during lockdown. The reported worsening in speech problems during lockdown was statistically insignificant (Table V). Parents/primary caregivers felt that the quantity of home-based therapy administered 
I feel as confident of taking care of my child during lockdown as before

My child appears to be bored during major part of the day during lockdown

Lockdown has adversely affected my child's therapy

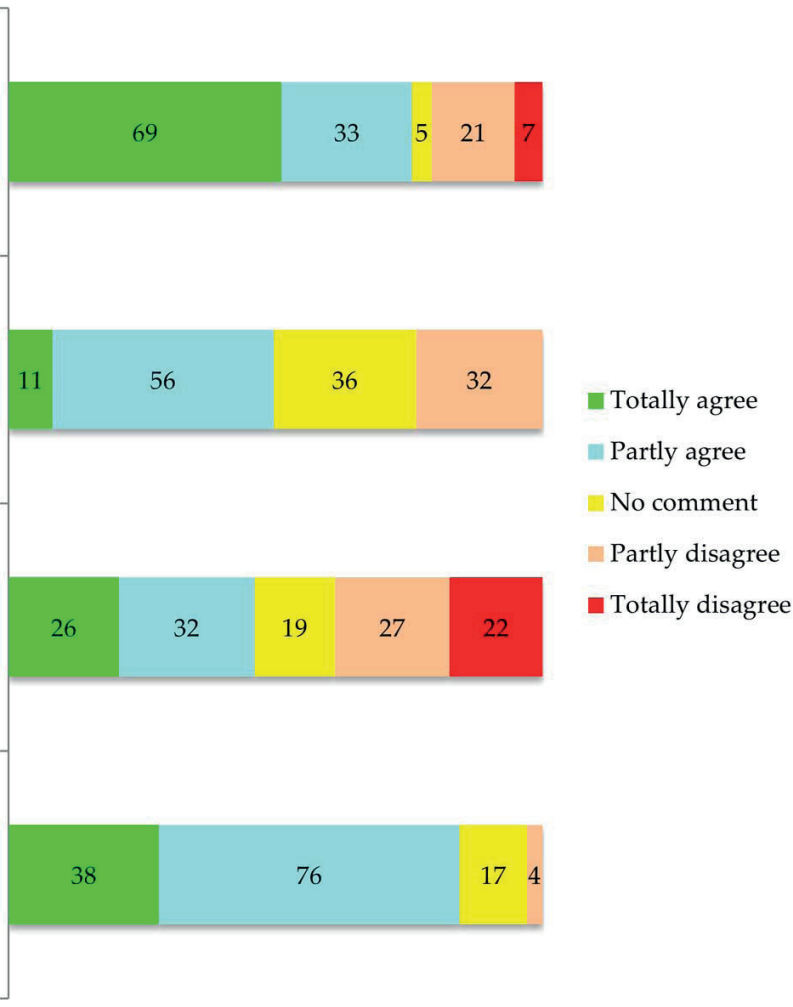

Fig. 3. Graphical representation of parental responses to 'Likert Scale Questionnaire: Part A'.

My overall quality of life during lockdown compared to what it was prior to lockdown

Child's speech during lockdown

Child's sleep-related problems during lockdown

Child's temper tantrums during lockdown

Child's interaction with parents and sibling(s) during lockdown

My child's behavioural problems during lockdown compared to those before lockdown

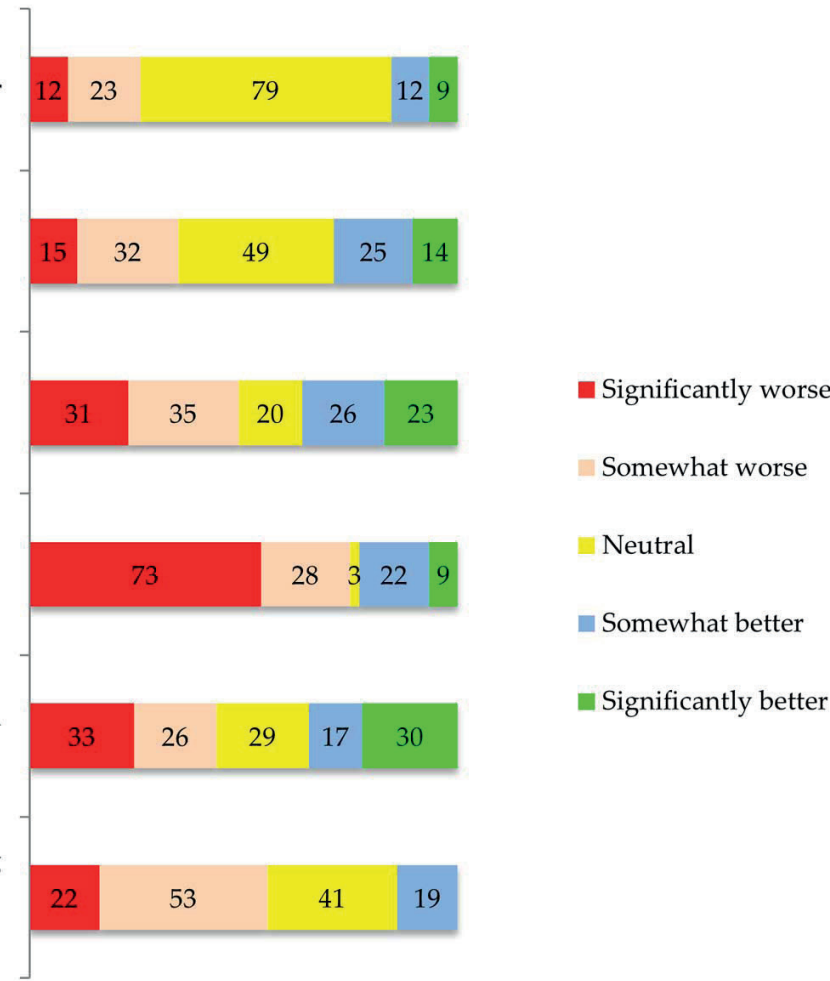

Fig. 4. Graphical representation of parental responses to ‘Likert Scale Questionnaire: Part B'. 


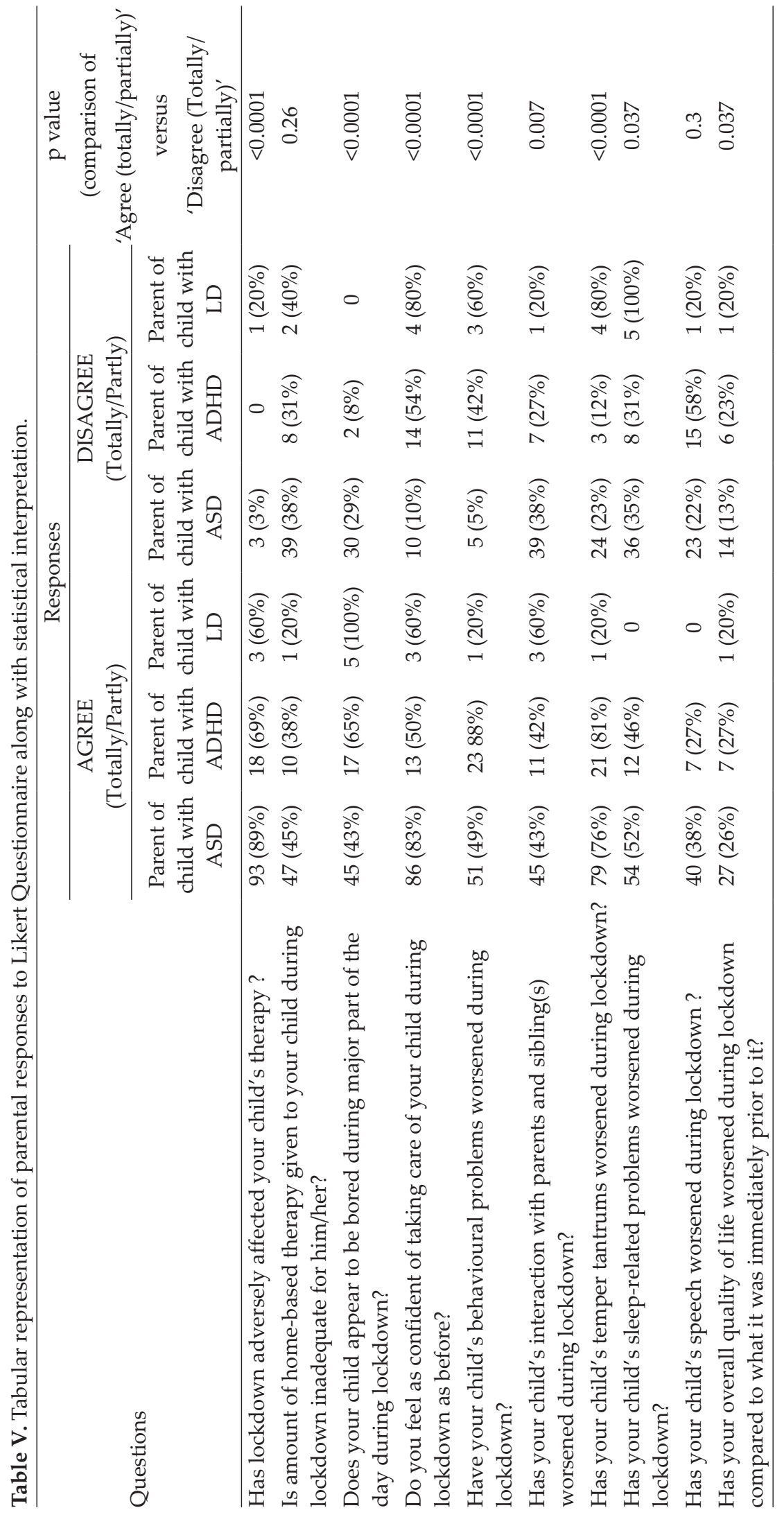


during lockdown was adequate. (Table V). Significantly larger number of parents/primary caregivers opined that their quality of lives had worsened during lockdown period compared to pre-lockdown period (Table V). However, the parents/primary caregivers of children with LD did not report significant worsening of their quality of lives.

\section{Discussion}

Lockdown due to the corona pandemic is a novel situation with possible impact in multiple sectors of societal functioning including routine healthcare delivery and rehabilitation services. In addition to the closure of various day-today social and professional activities except essential services, the lockdown also has socioeconomic and psychological dimensions. Children, more so those with special needs, stand to be affected due to the limited health care access during this period. ${ }^{3}$ Children with NDD form a significant proportion of clientele enrolled in regular pediatric neurology followup programmes. ${ }^{4}$ Hence, children with NDD form the target cohort in the current study.

ASD comprises of a large segment of NDD with varying prevalence ranging between $1-2 \%$. ${ }^{5,6}$ ADHD has been reported to have higher prevalence rates ranging upto $1.9 \%{ }^{7}$ In the index study, number of children with ASD significantly outnumbered those with ADHD and LD, probably reflecting differential prevalence as well as bias since the study was a hospital-based one. Moreover, regular institutional therapy was practiced for most ASD and some ADHD patients. Learning Disability management, on the other hand, hinges on a multimodal approach with remedial education measures being the pivot. $^{8}$

The study centres practiced institution-based interventions for NDD in consonance with current global practice where protocolized care is provided under closed supervision of trained personnel. The lockdown scenario drastically hampered institutional rehabilitation as depicted through the survey. Long-term effects of therapy discontinuation are yet to be evaluated. Though advocated in all, there are variable rates of compliance to home-based therapy as elucidated through the index survey. Adherence to a home-based rehabilitation programme depends on multiple factors such as motivation, social support and previous adherence to therapies. ${ }^{9}$ The lockdown scenario motivated parents/primary caregivers who were already administering home-based therapy to their children, to increase the number of activityhours and also led few to start administering these modalities afresh. This parental behaviour pattern is indicative of the fact that home-based therapy may be a feasible modality for ensuring continuity of rehabilitation of children with NDD in unexpected lockdown-like scenarios. In the absence of robust head-to-head trials between institutional versus home-based therapy, a hybrid approach may be advocated as an effective model. ${ }^{10}$ Such a model would be effective at times when institutional therapy is disrupted as in the case of the current lockdown.

COVID-19 pandemic is akin to a disaster-like situation which is likely to trigger immense psychological problems in general pediatric clientele' ranging from anxiety, behavioural issues, sleep disorders and anorexia. ${ }^{11}$ The psychological effects of this lockdown, specifically on children with NDD have not been published till date. Index survey hints at these behavioural issues by revealing significant parental concerns about increase in behavioural problems, temper tantrums, interaction and sleep issues though the perceived increase is not statistically significant. There is evidence to support the fact that disruptive behaviours of children with ADHD, rather than the disorder itself, significantly affects parental psychopathology and leads to parental stress. ${ }^{12}$ The survey is based on parental perceptions, which have a strong subjective element. Parental perceptions are crucial as parents form the core of the NDD management team. The successful implementation of any therapeutic programme in children with NDD is dependent on perspectives of parents/primary-caregivers. ${ }^{13}$ 
Hence, even though statistically insignificant, concerns about increased behavioural problems as in the index survey, need to be addressed. The perception of increased behavioural problems in children with NDD may be hypothesized to be secondary to the interplay of multiple factors such as therapy discontinuation, daily-routine alteration, monotony, excessive parental involvement, reflection of parental stress and undue expectations which all need to be addressed on an individualized fashion post lockdown relaxation. Children with milder variants of NDD may be additionally affected by their perceptions about the uncertain environment and fear psychosis as it has been adequately reported that exposures during natural disasters constitute a risk factor for poor psychological health in children and adolescents. ${ }^{14}$ In similar lines, 83\% among 2111 individuals up to the age of twenty-five years who had history of mental illness, remarked in a survey conducted in the United Kingdom that their conditions had deteriorated due to COVID-19 pandemic. ${ }^{15}$ These aspects were not considered in the current survey.

The strengths of the study are the simplistic design, relevant questions and emphasis on parental perceptions as highlighted above.

The most salient limitation of the study is its non-generalizability in the community setup as the study is a hospital-based one and the cohort is skewed towards ASD. Behavioural issues are more common in children with ASD and ADHD than with LD. Interventions to improve social skills is a major constituent of ASD rehabilitation programmes. ${ }^{16}$ It is intuitive to hypothesize that the disruption in these activities due to lockdown might have led to a surge in behavioural problems leading to the results of the survey. This may not be the issue with children with LD. Few entities that may be classified under the umbrella of NDD such as children with refractory epilepsy and Down syndrome were not included in the study.
Even two-year old children adversely affected by the disruption of their daily routines have been noted to become well adapted after adequate communication. ${ }^{17}$ Parental communication with children diagnosed with NDD is complex and depends on factors such as the nature and severity of the underlying disorder and parental motivation. This aspect was not factored in the current study design.

The earthquake in Italy had displayed that children with ASD who have been exposed to disasters, might have chronic psychological effects, which may be mitigated by early resumption of routine and targeted rehabilitation. ${ }^{18}$ In-depth psychological review, which could give an early indication of the impending effects, has not been performed in the current survey. Factors such as age, socioeconomic status, educational qualifications and psychological status of the parents/primary caregivers are likely to affect their responses. These were not taken into account in the study.

To conclude, lockdown during the Corona pandemic is a unique situation, whose multidimensional effects on children with NDD and their parents/primary caregivers were explored through an online, multi-centric questionnaire-based survey. Children with ASD, ADHD and LD between one to twelve years of age were enrolled. Discontinuation of multimodal institutional therapies was noted to be a significant effect of the lockdown. Homebased therapies were continued mostly by those, who were already receiving this modality earlier. There was no significant discontinuation of pharmacotherapy during lockdown. Parents/ primary caregivers perceived that their children had increase in behavioural issues and that their quality of lives deteriorated during lockdown. Among the subsets of children, those with ASD and ADHD were maximally affected. However, most parents felt confident that they would be able to continue providing adequate care of their children. The survey points to the role of regular home-based therapy in children with 
NDD, especially to tide over similar unexpected scenarios. An open feedback loop between healthcare providers and parents based on a web-based platform may be hypothesized to be useful and needs to be studied. Re-evaluating the children after the pandemic using assessment tools and combining the results would make the study more valuable.

\section{Author contribution}

The authors confirm contribution to the paper as follows: Study conception and design: JNG, SR Data collection: SR,VS,AKS,MB,JNG Analysis and interpretation of results:VS,SR,JNG Draft manuscript preparation: JNG,MB All authors reviewed the results and approved the final version of the manuscript.

\section{Ethical approval}

The Institutional Ethical Committee approved the study and it was registered with the Clinical Trials Registry-India (CTRI) (No: CTRI/2020/06/025795).

\section{Source of funding}

Nil.

\section{Conflicts of interest}

Nil.

\section{REFERENCES}

1. WHO Director-General's opening remarks at the media briefing on COVID-19-11 March 2020. World Health Organization. Available at: https://www. who.int/director-general/speeches/detail/whodirector-general-s-opening-remarks-at-the-mediabriefing-on-covid-19---11-march-2020 (Accessed on March 11, 2020).

2. Arim RG, Miller AR, Guèvremont A, Lach LM, Brehaut JC, Kohen DE. Children with neurodevelopmental disorders and disabilities: a population-based study of healthcare service utilization using administrative data. Dev Med Child Neurol 2017; 59: 1284-1290.
3. Lazzerini M, Barbi E, Apicella A, Marchetti F, Cardinale F, Trobia G. Delayed access or provision of care in Italy resulting from fear of COVID-19. Lancet Child Adolesc Health 2020; 4: e10-e11.

4. Thapar A, Cooper M, Rutter M. Neurodevelopmental disorders. Lancet Psychiatry 2017; 4: 339-346.

5. Christensen DL, Braun KV, Baio J, et al. Prevalence and characteristics of autism spectrum disorder among children aged 8 years-autism and developmental disabilities monitoring network, 11 sites, United States, 2012. MMWR Surveill Summ 2018; 65: 1-23.

6. Chiarotti F, Venerosi A. Epidemiology of autism spectrum disorders: a review of worldwide prevalence estimates since 2014. Brain Sci 2020; 10: 274.

7. Russell G, Rodgers LR, Ukoumunne OC, Ford T. Prevalence of parent-reported ASD and ADHD in the UK: findings from the Millennium Cohort Study. J Autism Dev Disord 2014; 44: 31-40.

8. Dalwai S, Ahmed S, Udani V, Mundkur N, Kamath SS, C Nair MK; National Consultation Meeting for Developing IAP Guidelines on Neuro Developmental Disorders under the aegis of IAP Childhood Disability Group and the Committee on Child Development and Neurodevelopmental Disorders. Consensus statement of the Indian Academy of Pediatrics on evaluation and management of autism spectrum disorder. Indian Pediatr 2017; 54: 385-393.

9. Essery R, Geraghty AW, Kirby S, Yardley L. Predictors of adherence to home-based physical therapies: a systematic review. Disabil Rehabil 2017; 39: 519-534.

10. Leaf JB, Leaf R, McEachin J, Cihon JH, Ferguson JL. Advantages and challenges of a home-and clinic-based model of behavioral intervention for individuals diagnosed with autism spectrum disorder. J Autism Dev Disord 2018; 48: 2258-2266.

11. Jiao WY, Wang LN, Liu J, et al. Behavioral and emotional disorders in children during the COVID-19 epidemic. J Pediatr 2020; 221: 264-266.e1.

12. Gökçen C, Özatalay E, Fettahoğlu EÇ. Family functioning and psychological symptoms in parents of children with attention deficit and hyperactivity disorder. Turk J Child Adolesc Ment Health 2011; 18: 95-104.

13. Breik N, Fan Kuo I, Bugden S, Moffat M, AlessiSeverini S. Treating children with ASD: the perspective of caregivers. J Pharm Pharm Sci 2018; 21: 74s-87s.

14. Masten AS, Osofsky JD. Disasters and their impact on child development: introduction to the special section. Child Dev 2010; 81: 1029-1039. 
15. Lee J. Mental health effects of school closures during COVID-19. Lancet Child Adolesc Health 2020; 4: 421.

16. McConnell SR. Interventions to facilitate social interaction for young children with autism: review of available research and recommendations for educational intervention and future research. J Autism Dev Disord 2002; 32: 351-372.
17. Dalton L, Rapa E, Stein A. Protecting the psychological health of children through effective communication about COVID-19. Lancet Child Adolesc Health 2020; 4: 346-347.

18. Valenti M, Ciprietti T, Di Egidio C, et al. Adaptive response of children and adolescents with autism to the 2009 earthquake in L'Aquila, Italy. J Autism Dev Disord 2012; 42: 954-960. 